of this organism was possible up to 14 days with a two-minute daily shake of the monomer/test-culture mixture. These results confirmed those made by one of the makers (private communication). It is probable that the watery film acts as a protective layer round the micro-organisms, as the broth culture and monomer are immiscible liquids.

Neither monomer dried on filter paper or applied directly in a ditch nor resin discs had any direct inhibitory action towards any of the test organisms when tested routinely. This is at variance with the findings of Sokolowski et al. (1955), who reported "remarkable bacteriostatic activity" with the Czech product Spofacryl.

An 18-hour culture of coagulase-positive staphylococcus scraped from an agar plate direct into monomer resulted in the formation of a brittle residue which was incubated in the monomer for 24 hours at $37^{\circ} \mathrm{C}$. This residue, plated out, gave no growth after 18 hours' incubation, but the residue appeared to be more friable and then spread easily. The test organism was recovered after reincubation for a further period of 18 hours. None of the other test organisms survived in this test. $B$. cereus was not used, as it had shown prolonged survival in broth culture and monomer.

\section{Comment}

These results suggest that some pathogens can remain viable in the cured resin for varying times and to a lesser degree in the monomer, and that for all surgical procedures in the human body only the presterilized material should be used. The monomer should not be put up in rubber-capped bottles, because extraction of the rubber may occur and contamination of the monomer can be introduced, particularly if all the liquid is not used at once. The ampoules should be kept in the dark until required, as sunlight changes the monomer. Ideally the ampoules should themselves be of dark glass. The strictest asepsis should be observed in all the manipulative procedures involved in its use. Two pairs of gloves should be worn by those who knead the resin because of the tensile strains induced in the gloves by the manipulation and the ease with which punctures can be enlarged.

\section{Summary}

The viability of some common pathogens in cold-curing acrylic resin (monomethyl methacrylate) is shown.

Beta-haemolytic streptococci are quickly killed in the fluid monomer; Staphylococcus pyogenes survived 10 to 20 minutes' exposure, while the spore-forming Bacillus cereus remained viable after up to 14 days' exposure.

These resin materials for surgical procedures should be presterilized in suitable quantities for immediate use, and not taken from packs which favour multiple use.

This work has been carried out under the auspices of the Leverhulme Trust Fund.

\section{REFERENCES}

Charnley, J. (1960). F. Bone 7t Surg., 42B, 28.

Dutton, J. (1959). Brit. med. F., 2, 597.

Judet, J., Judet, R., Lagrange, J., and Dunoyer, J. (1954). ResectionReconstruction of the Hip: Arthroplasty with an Acrylic Prosthesis, edited by K. I. Nissen. London.

Oliver, L

Sokolowski, S., Freytag, T., and Kmita, S. (1955). Neurol. Neurochir. Psychiat. pol., 5, p. 253.

\title{
Clinical Trial with Ambilhar in Schistosoma mansoni Infections in Tanzania
}

\author{
J. E. MCMAHON,* M.R.C.S., L.R.C.P. ; C. P. KILALA,* M.B., B.S.
}

Brit. med. F., 1966, 2, 1047-1049

Ambilhar (Ciba 32,644-Ba) is a nitrothiazole derivative, 1-(5nitro-2-thiazolyl)-2-imidazolidinone. Studies have not yet clarified its exact mode of antiparasitic action. It is active only if present in the non-metabolized form, and it is metabolized rapidly by a normal liver.

Promising early reports were published regarding this drug's effectiveness in the treatment of schistosomiasis and amoebiasis. Woodruff (1966) pointed out that the popular press have inferred that the drug is safe for general use, and further " that no paper permitting critical appraisal of the toxicity of the drug in man has yet appeared in a major medical journal."

In this paper we report our findings on its effectiveness as evidenced by follow-up examinations two and four months after completion of treatment, and on observed side-effects during therapy.

\section{Materials and Methods}

Ambilhar was given to 92 African in-patients $(25 \mathrm{mg} . / \mathrm{kg}$. daily in two divided doses for seven days). All the patients were Africans who originated from an area around Mwanza,

* Bast African Institute for Medical Research, Mwanza, Tanzania. on the southern shores of Lake Victoria. Seventy-one returned for the two-month and 63 for the four-month follow-up examinations.

Two different methods were used for detecting eggs in stools: the A.M.S. III technique (Hunter et al., 1948), in which three 1-g. aliquots were examined for Schistosoma mansoni eggs; and the quantitative filtration staining technique (Bell, 1963), which enabled calculation of egg excretion per 24 hours, the sensitivity of the method being sufficient to detect an output of 1,000 eggs per day. Viability of eggs was demonstrated by the hatching test. "Cures" were considered to have occurred only when all three tests were negative.

All patients were clinically examined before, during, and after treatment, and a careful note was made of all side-effects. The majority had pre- and post-treatment electrocardiograms taken.

\section{Results}

The patients were divided into three groups according to pretreatment egg load per 24 hours : group 1, less than 10,000; group 2, 10,000-100,000; and group 3, 100,000-500,000. 
Table I shows the mean percentage reduction in egg load, and the "cure rate," as assessed by the three techniques, at the two- and four-month follow-up examinations. Of the "uncured" patients, four in group 1, three in group 2, and four in group 3 missed at least one dose.

\section{TABLE I}

\begin{tabular}{|c|c|c|c|c|}
\hline $\begin{array}{c}\text { Pretreatment Egg } \\
\text { Excretion per } 24 \text { hours }\end{array}$ & $\begin{array}{l}\text { "Cure" } \\
\text { at } 2 \\
\text { months }\end{array}$ & $\begin{array}{l}\text { Mean } \\
\text { Reduction } \\
\text { in Egg } \\
\text { Load }\end{array}$ & $\begin{array}{l}\text { "Cure" } \\
\text { at } 4 \\
\text { months }\end{array}$ & $\begin{array}{c}\text { Mean } \\
\text { Reduction } \\
\text { in Egg } \\
\text { Load }\end{array}$ \\
\hline $\begin{array}{lll}\text { Group } 1 . & <10,000 \\
\text { Group } 2 . & 10,000-100,000 & \cdots \\
\text { Group 3. } & 100,000-500,000 & \ldots\end{array}$ & $\begin{array}{l}14 / 28^{*} \\
11 / 30 \\
2 / 13\end{array}$ & $\begin{array}{l}92 \cdot 7 \% \\
99.7 \% \\
84.3 \%\end{array}$ & $\begin{array}{r}12 / 24 \\
7 / 27 \\
4 / 12\end{array}$ & $\begin{array}{l}76.1 \% \\
97.5 \% \\
79.5 \%\end{array}$ \\
\hline
\end{tabular}

* Numerator $=$ number cured. Denominator $=$ number examined.

The highest cure rate was obtained in the patients with light infections (group 1) and the greatest reduction in egg load occurred in the moderate-to-severe infections (group 2). Patients with very heavy infections (group 3 ) had both lowest cure rate and at two months the least reduction in egg output. The four-month reduction in egg output in group 1 may be due to some cases becoming reinfected.

In Table II the groups are further subdivided according to age. Cure rates at two months were $0 / 7$ (0-11 years), 12/26 (12-18 years), $15 / 38$ (18 + years). These results suggest that children are more resistant to treatment than adolescents and adults. The $\chi^{2}$ test showed the observed differences between the adolescent and adult groups to be statistically insignificant. Table III compares the sensitivity of the three techniques in assessing the cure rate. The hatching test was the most sensitive of the three methods used, and the filtration staining technique slightly more sensitive than the A.M.S. III.

\begin{tabular}{|c|c|c|c|c|c|c|c|c|}
\hline \multirow{2}{*}{$\begin{array}{l}\text { Age in } \\
\text { Years }\end{array}$} & \multicolumn{3}{|c|}{ "Cure" at 2 months } & \multirow{2}{*}{$\begin{array}{l}\text { Mean } \\
\text { Reduc- } \\
\text { tion } \\
\text { in Egg } \\
\text { Load }\end{array}$} & \multicolumn{3}{|c|}{ "Cure" at 4 months } & \multirow{2}{*}{$\begin{array}{c}\text { Mean } \\
\text { Reduc- } \\
\text { tion } \\
\text { in Egg } \\
\text { Load }\end{array}$} \\
\hline & Gp. 1 & Gp. 2 & Gp. 3 & & Gp. 1 & Gp. 2 & Gp. 3 & \\
\hline $\begin{array}{c}0-11 \\
12-18 \\
18+\end{array}$ & $\begin{array}{l}0 / 2 \\
6 / 9 \\
8 / 17\end{array}$ & $\begin{array}{l}0 / 1 \\
4 / 10 \\
7 / 19\end{array}$ & $\begin{array}{l}0 / 4 \\
2 / 7 \\
0 / 2\end{array}$ & $\begin{array}{l}91 \cdot 1 \% \\
94.4 \% \\
91.2 \%\end{array}$ & $\begin{array}{l}0 / 2 \\
5 / 6 \\
7 / 16\end{array}$ & $\begin{array}{l}0 / 1 \\
2 / 9 \\
5 / 17\end{array}$ & $\begin{array}{l}0 / 4 \\
3 / 6 \\
1 / 2\end{array}$ & $\begin{array}{l}76.0 \% \\
92.6 \% \\
84.5 \%\end{array}$ \\
\hline
\end{tabular}

\begin{tabular}{|c|c|c|c|c|c|}
\hline \multicolumn{3}{|c|}{ 2-month "Cure Rate" } & \multicolumn{3}{|c|}{ 4-month " Cure Rate" } \\
\hline AMS III & $\begin{array}{l}\text { Filtration } \\
\text { Staining }\end{array}$ & $\underset{\text { Test }}{\text { Hatching }}$ & AMS III & $\begin{array}{l}\text { Filtration } \\
\text { Staining }\end{array}$ & $\begin{array}{c}\text { Hatching } \\
\text { Test }\end{array}$ \\
\hline 44 & 40 & 28 & 42 & 34 & 25 \\
\hline
\end{tabular}

\section{Side-effects}

Children tolerated the drug better than adults. Minor drug reactions occurred in all age groups, and more serious sideeffects in adolescents and adults. The following were the reactions observed:

\section{Central Nervous System}

Most patients complained of varying degrees of headache. General weakness, dizziness, and insomnia were not uncommon complaints, but the most serious effects on the C.N.S. were drug-induced epilepsy and psychosis. In all cases reported below extensive investigations into the background of the patients revealed no previous histories of epilepsy or psychotic tendencies.

Case 43.-A labourer aged 24 had his first grand-mal attack in the early morning of the fourth day of treatment. The drug was stopped, but two days later he became mentally confused, talked irrationally, and had his second fit that same evening. A week after the cessation of treatment he was still mentally dull and lethargic. Subsequently he gradually improved and returned to work.

Case 54.-A labourer aged 35 was given Ambilhar a few days after disappearance of jaundice. His liver was four fingerbreadths enlarged when treatment began. A grand-mal attack occurred on the evening of the second day of treatment. The drug was stopped and he suffered no more attacks.

Case 80.-A schoolgirl aged 17 had a fit during the fourth day of treatment. The drug was stopped; there were no further attacks, and she was discharged from the ward three days later.

Case 62.-A male school-teacher aged 30 developed marked psychotic changes on the fourth day of treatment. He became irrational and aggressive. Twenty-four hours after the cessation of Ambilhar, and the beginning of chlorpromazine and paraldehyde therapy, obvious improvement began. $\mathrm{He}$ was discharged three days later.

Case 17.-A man aged 43 showed marked mental confusion on the fifth day of treatment. His condition improved within 24 hours of the cessation of treatment.

\section{Cardiovascular System}

Moderate tachycardia was common, and the pulse rate tended to be highest on the fifth day of treatment. Irregular pulses in three adolescents on the third and fourth days were due to extrasystoles.

Other than a decreased voltage of the $\mathrm{T}$-wave in the precordial leads no electrocardiographic changes were noted.

Case 2.-A man aged 25 suffered severe epistaxis on the sixth day of treatment. The bleeding continued for several hours. Ambilhar was stopped and he was sedated with phenobarbitone. During the day he vomited blood and bile and there was marked tenderness of the thoracic spine. Next day the total white blood count was $9,000 /$ c.mm. (polymorpholeucocytes $60 \%$, lymphocytes $30 \%$, eosinophils $7 \%$, monocytes $3 \%$ ). The serum glutamic oxaloacetic transaminase was 115 units. Unfortunately, it was not possible to examine the prothrombin time. Five days after the onset of symptoms his general condition was satisfactory and he was discharged from the ward.

\section{Alimentary System}

Nausea and abdominal pain were common complaints. Vomiting occurred among $15 \%$ of adults, but was seldom severe enough to warrant cessation of therapy.

\section{Discussion}

Six $(6.5 \%)$ of 92 patients treated had severe drug reactions. In five of these the side-effects were reversible within a rew days of cessation of therapy. One patient (Case 43), whose drug manifestations included both convulsions and psychic changes, took more than a week to return to normal.

It is probable that poor liver function predisposes to the drug's inducing serious toxic effects. Case 54 had an enlarged liver, and a few days before therapy was jaundiced. Owing to an acute senior staff shortage, we were unable to carry out liver-function tests and other chemical analyses on those patients who had severe drug reactions. These tests would be useful in assessing the predisposing factors to the drug's toxicity.

Our investigations do not support the view that side-reactions may be due to allergic manifestations after the liberation of antigens from autolysed worms. In another trial (in press) we found that the use of antihistamines in conjunction with Ambilhar in no way reduced side-effects. Of the six serious cases described above five had light infections and one a heavy infection, as assessed by pretreatment egg load-that is, severity 
TABLE IV

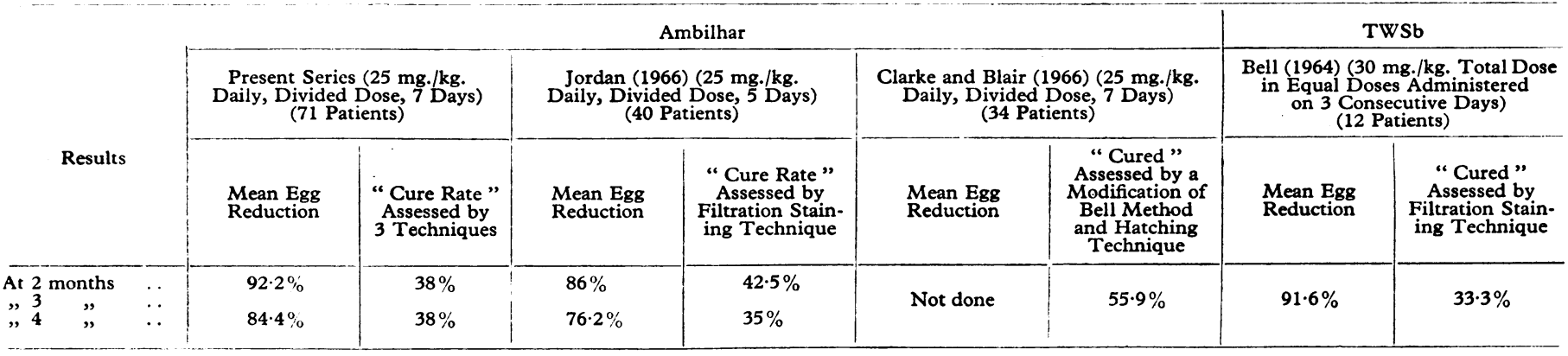

of side-effects were not related to apparent intensity of infection.

Although no work seems to have been published demonstrating a direct relation between worm load and egg excretion in $S$. mansoni infections in man, enough presumptive evidence exists to infer that during the course of the disease, as tissue fibrosis increases and some form of immune mechanism results in worm "stunting" and death, the egg-excretion rate decreases and in some cases ceases completely. Our experiments with $S$. mansoni infections in baboons certainly support this view.

In schistosomiasis no rapid immunological technique has yet been devised for demonstrating a parasitological cure. As a measure of drug efficiency, the mean percentage reduction in egg load (Bell, 1964) and the viability of eggs, as shown by the hatching test, appear to be the two most valuable tests at present in use. Insufficient work has been done throughout the $S$. mansoni endemic areas of the world to enable a satisfactory comparison of different drug regimens to be made. Many workers ignore a quantitative approach and use crude, insensitive, qualitative methods in attempting to assess drug efficiency.

The difference in results between both Tanzanian Ambilhar trials and the Astiban trial are statistically insignificant (Table IV).

In the modification of the Bell technique used in the Rhodesian trial a sample of stool weighing $5 \mathrm{~g}$. was employed for both counting and hatching. This method is far less sensitive than those we used, and this should be taken into account when considering their apparently high cure rate.

It appears that the effectiveness of Ambilhar in the dosage used compares favourably with that of TWSb given in a total dose of $30 \mathrm{mg}$. $/ \mathrm{kg}$. body weight. Children appear more resistant to treatment than adults, and also they have better toleration of the drug. In a recent trial McMahon (in press) gave children $40 \mathrm{mg}$. $/ \mathrm{kg}$. daily for five days, and drug toleration was much better than was the case when adults were given $25 \mathrm{mg}$. $/ \mathrm{kg}$. daily.

From our clinical observations in this trial we conclude that, because of the serious side-effects encountered, this drug should be used only under strict medical supervision. It is not suitable for mass treatment of adults.

Past medical histories of psychosis or epilepsy are definite contraindications to the drug. Careful medication is warranted where there is evidence of poor liver function or myocardial damage. In such cases it should be given in the minimum effective dosage.

\section{Summary}

Ambilhar in a dosage of $25 \mathrm{mg}$. $/ \mathrm{kg}$. body weight/day for seven days was given to 92 patients infected with Schistosoma mansoni.

The effectiveness of the drug appears to compare favourably with Astiban in a total dose of $30 \mathrm{mg}$. $/ \mathrm{kg}$. body weight, particularly when the mean percentage reduction in egg output is used as an index of drug efficiency.

Children are more resistant to treatment, and also tolerate the drug better than do adults.

Serious drug reactions encountered were epileptiform seizures, psychoses, and epistaxis. Because of these reactions it is recommended that this drug should not be used for mass treatment of adults.

We are indebted to the Secretary-General, East African Common Services Organization, Nairobi, for permission to publish this paper. Our thanks are also due to Ciba Limited, Basle, for generous supplies of Ambilhar and to Dr. J. Bleakley, Ciba Limited, Salisbury, for his advice and cooperation.

\section{REFERENCES}

Bell, D. R. (1963). Bull. Wld Hlth Org., 29, 525.

(1964). Ann. trop. Med. Parasit., 58, 219.

Clarke, V. de V., and Blair, D. M. (1966). Cent. Afr. F. Med., 12, 64. Hunter, G. W. Hodges, E. P., Jahnes, W. G., Diamond, L. S., and Ingalls, J. W., jun. (1948)." Bull. U.S. Army med. Dep., 8, 128.

Jordan, P. (1966). Brit. med. F., 1, 276.

Woodruff, A. W. (1966). Ibid., 1, 291. 